\title{
Correction to: Impact of the exotic fall armyworm on larval parasitoids associated with the lepidopteran maize stemborers in Kenya
}

\author{
Bonoukpoè Mawuko Sokame - Julius Obonyo • Enock Mwangangi Sammy • \\ Samira A. Mohamed - Sevgan Subramanian - Dora Chao Kilalo • \\ Gerald Juma $\cdot$ Paul-André Calatayud
}

Published online: 2 November 2020

(C) International Organization for Biological Control (IOBC) 2020

Correction to: BioControl

https://doi.org/10.1007/s10526-020-10059-2

There was a typo in the fifth author's name in the initial online publication. The original article has been corrected.

A1 The original article can be found online at https://

A2 doi.org/10.1007/s10526-020-10059-2.

A3 B. M. Sokame $(\bowtie) \cdot$ J. Obonyo ·

A4 E. M. Sammy - S. A. Mohamed - S. Subramanian ·

A5 P.-A. Calatayud

A6 International Centre of Insect Physiology and Ecology

A7 (ICIPE), P.O. Box 30772-00100, Nairobi, Kenya

A8 e-mail: bsokame@icipe.org; jsokame@gmail.com

A9 B. M. Sokame · D. C. Kilalo

A10 Department of Plant Science and Crop Protection,

A11 University of Nairobi, Kangemi,

A12 P.O. Box, 29053, Nairobi 00625, Kenya

A13 G. Juma

A14 Department of Biochemistry, University of Nairobi,

A15 P.O. Box 30197, Nairobi 00100, Kenya

A16 P.-A. Calatayud

A17 CNRS, IRD, UMR Évolution, Génomes, Comportement

A18 et Écologie, Université Paris-Saclay,

A19 91198 Gif-sur-Yvette, France 